\title{
ГЕОГРАФИЯ ПУБЛИКАЦИОННОЙ АКТИВНОСТИ ВЕДУЩИХ ЖУРНАЛОВ ПО ГРУППЕ НАУЧНОЙ СПЕЦИАЛЬНОСТИ 25.00.00 - НАУКИ О ЗЕМЛЕ (НА ПРИМЕРЕ ЖУРНАЛОВ «ГЕОГРАФИЯ И ПРИРОДНЫЕ РЕСУРСЫ», «ВЕСТНИК МОСКОВСКОГО УНИВЕРСИТЕТА. СЕРИЯ 5. ГЕОГРАФИЯ» И «ВЕСТНИК ВОРОНЕЖСКОГО ГОСУДАРСТВЕННОГО УНИВЕРСИТЕТА. СЕРИЯ: ГЕОГРАФИЯ. ГЕОЭКОЛОГИЯ») ЗА 2017 ГОД
}

\author{
В.А. Табунщик \\ Крымский федеральный университет имени В. И. Вернадского, Россия \\ Поступила в редакциюю 3 февраля 2019 г.
}

\begin{abstract}
Аннотация: В статье приведен анализ публикационной активности трех ведущих журналов по группе научной специальности 25.00.00 - науки о Земле (на примере журналов «География и природные ресурсы», «Вестник Московского университета. Серия 5. География» и «Вестник Воронежского государственного университета. Серия: География. Геоэкология») с использованием данных научной электронной библиотеки - https://elibrary.ru/. Приводится методика по оценки публикационной активности журналов. Рассмотрено общее количество статей в каждом журнале, аффилированность авторов с местами их работы и география субъектов Федерации, которые они представляют. За 2017 год было издано 6 выпусков журнала «Вестник Московского университета. Серия 5. География», 4 выпуска журнала «Вестник Воронежского государственного университета. Серия: География. Геоэкология» и 4 выпуска журнала «География и природные ресурсы». Всего за 2017 год было проанализировано 74 публикации журнала «Вестник Московского университета. Серия 5. География», 84 публикации журнала «Вестник Воронежского государственного университета. Серия: География. Геоэкология» и 88 публикаций журнала «География и природные ресурсы», в среднем на один выпуск журнала приходится 12, 21 и 22 публикации соответственно. Приводятся карты публикационной активности для каждого журнала и дается их анализ.
\end{abstract}

Ключевые слова: библиометрия, публикация, Scopus, Web of Science, наука, рейтинг, география, карта.

The geography of publication activity of the leading journals in the scientific specialty group 25.00.00 - Earth sciences (using the examples of the journals «Geography and Natural Resources», «Moscow University Bulletin. Series 5. Geography» and «Proceedings of Voronezh State University. Series: Geography. Geoecology») for 2017 year

V.A. Tabunshchik

Abstract: In the article an analysis of the publication activity of three leading journals in the group of scientific specialties 25.00.00 - Earth sciences (using the examples of the journals «Geography and Natural Resources», «Moscow University Bulletin. Series 5. Geography» and «Proceedings of Voronezh State University. Series: Geography. Geoecology») using the data of the scientific electronic library - https:// elibrary.ru/ are provided. The methodology for evaluating the publication activity of journals is given. The

() Табунщик В.А., 2019 
total number of articles in each journal, the affiliation of authors with their places of work and the geography of the subjects of the Federation they represent are considered. In 2017, 6 issues of the journal «Moscow University Bulletin. Series 5. Geography», 4 issues of the journal «Proceedings of Voronezh State University. Series: Geography. Geoecology» and 4 issues of the journal «Geography and Natural Resources». In total for 2017, 74 publications of the journal «Moscow University Bulletin. Series 5. Geography», 84 publications of the journal «Proceedings of Voronezh State University. Series: Geography. Geoecology» and 88 publications of the journal «Geography and Natural Resources», on average, there are 12, 21 and 22 publications per issue of the journal, respectively. The publication activity maps for each journal are given and their analysis is given.

Key words: bibliometrics, publication, Scopus, Web of Science, science, rating, geography, map.

\section{ВВЕДЕНИЕ}

Публикационная активность является важным фактором, определяющим статус ученого и научной организации. Параллельно с этим качество публикаций ученых отражает качество научного журнала. Одновременно с этим сами научные журналы заинтересованы в том, чтобы на их страницах были опубликованы лучшие работы, отражающие самые передовые научные исследования. В связи с этим география публикационной активности должна быть как можно шире, чтобы донести нужную информацию до конечного потребителя ученого.

В последние годы тема публикационной активности внимательно исследуется, о чем свидетельствует большое количество научных работ по этой проблематике.

Так, широкий круг работ направлен на изучение публикационной активности профессорскопреподавательского состава и организации в целом [3, 5, 7, 9, 17, 19], публикационной активности студентов [1, 2], публикационной активности как средства оценки качества деятельности сотрудников [6, 10, 12, 14], методики оценки публикационной активности $[8,11,13,15,16]$, публикационной активности журналов $[4,8,18,20]$ и прочее.

Однако, недостаточно освещается такая сторона вопроса как география публикационной активности.

Цель статьи - изучить географию публикационной активности ведущих рецензируемых научных изданий Российской Федерации, в которых должны быть опубликованы основные научные результаты диссертаций на соискание ученой степени кандидата наук и ученой степени доктора наук по группе научной специальности 25.00.00 - науки о Земле.

\section{МАТЕРИАЛЫ И МЕТОДЫ}

Под географией публикационной активности понимается географическое распределение публикаций, аффилированных с авторами и научными организациями, в которых осуществляют научную деятельность авторы, приславших свои работы в рассматриваемые журналы по административнотерриториальным единицам. В качестве таких единиц в статье выступают субъекты Российской Федерации.

Методика работы состоит в следующем.

1. Подбор перечня журналов, для которого будут произведены измерения.

2. Установление данных о аффиляции публикаций с авторами и с научными организациями, которые они представляют для каждого номера журнала. Если одна публикация имеет в статье несколько соавторов, и они представляют одну организацию, то учитывается, что работа полностью выполнена в одной организации, а если соавторы из разных организаций (или один автор аффилирует себя с разными организациями), то работа учитывается для каждой организации. Если у автора имеется более одной публикации в журнале, то они рассматриваются как отдельные публикации. Далее происходит установление географического распределения публикаций в разрезе стран и субъектов Российской Федерации.

3. Создание серии карт, отражающих публикационную активность журналов, с использованием геоинформационных систем, распространяемых по открытой лицензии (программный комплекс Quantum GIS-QGIS) на территории Российской Федерации.

В статье использованы литературно-аналитический, сравнительно-географический, исторический, статистический, математический, геоинформационный методы исследования.

В связи с невозможностью полностью охватить в одной работе географию публикационной активности журналов с момента их основания, в данном исследовании приводится анализ публикационной активности журналов за 2017 год.

В качестве исследуемых были выбраны три российских журнала, входящих в перечень рецензируемых научных изданий Российской Федера- 


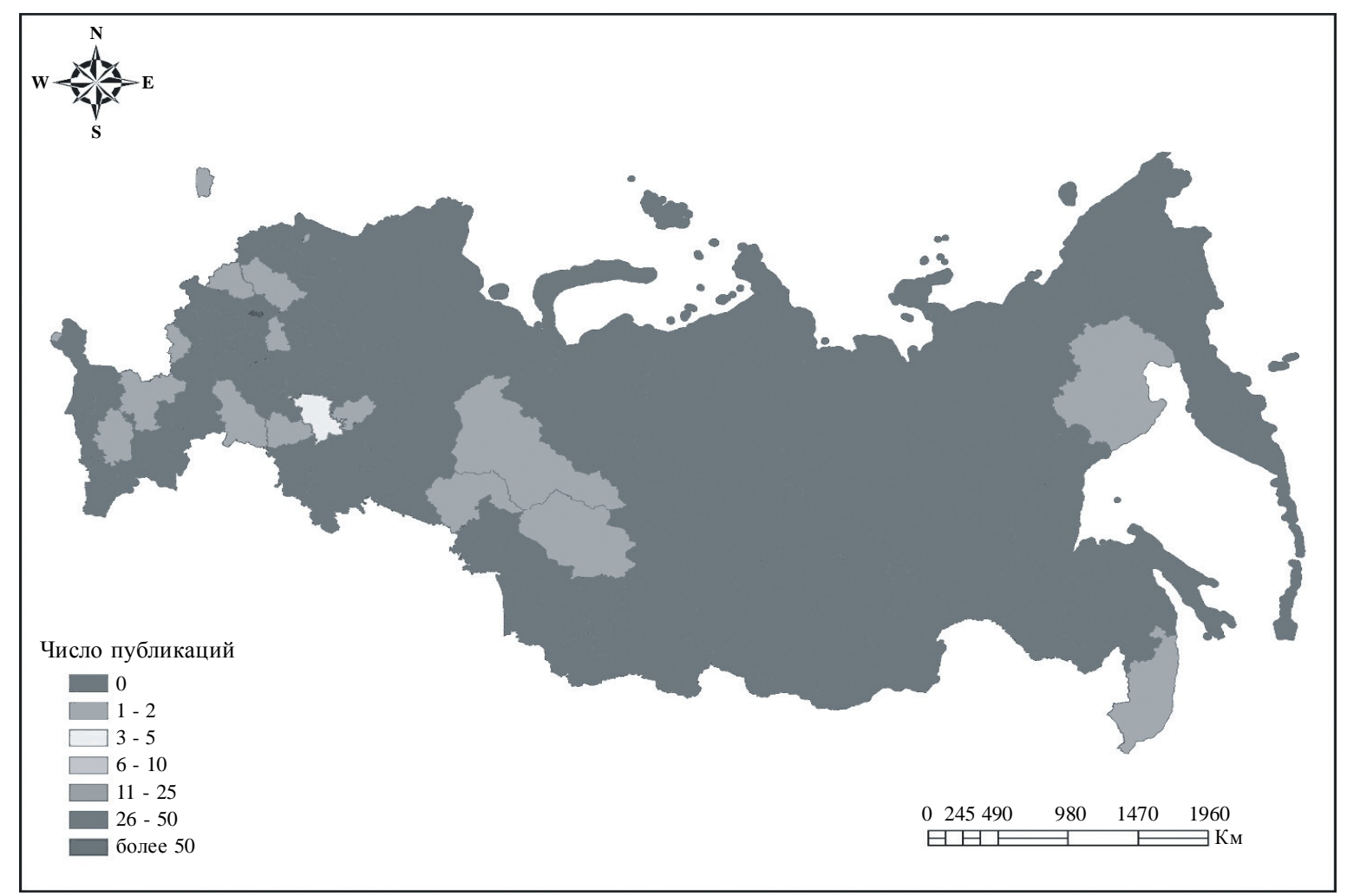

Puc. 1. География публикационной активности журнала «Вестник Московского университета. Серия 5. География» за 2017 год (построено с использование открытых наборов геоданных - OpenStreetMap)

ции, в которых должны быть опубликованы основные научные результаты диссертаций на соискание ученой степени кандидата наук и ученой степени доктора наук по группе научной специальности 25.00.00 - науки о Земле.

1. Вестник Московского университета. Серия 5. География (Издательство ФГБОУ ВО «Московский государственный университет им. М.В. Ломоносова», г. Москва).

2. Вестник Воронежского государственного университета. Серия: География. Геоэкология (Издательство ФГБОУ ВО «Воронежский государственный университет», г. Воронеж).

3. География и природные ресурсы (Общество с ограниченной ответственностью «Академическое издательство «Гео», г. Новосибирск).

Причем все три журнала, как подчеркивается на их официальных страницах в сети Интернет, входят в международные реферативные базы данных и системы цитирования («Вестник Московского университета. Серия 5. География» и «География и природные ресурсы» входят в базу данных Scopus, а «Вестник Воронежского государственного университета. Серия: География. Геоэкология» - в базу данных Web of Science).
Данные о количестве статей в каждом выпуске и аффиляции авторов статей анализировались из научной электронной библиотеки - https:// elibrary.ru/. Если автор аффилирован с двумя организациями, которые расположены на территории различных субъектов Российской Федерации - то одна и та же работа учитывалась для каждой организации. В данном исследовании учитывались только научные статьи, опубликованные в журналах и не учитывались обзорные статьи, сообщения о юбилеях, потерях науки, обзоры и рецензии, хроника и прочая информация.

\section{РЕЗУЛЬТАТЫ И ОБСУЖДЕНИЕ}

За 2017 год было издано 6 выпусков журнала «Вестник Московского университета. Серия 5. География», 4 выпуска журнала «Вестник Воронежского государственного университета. Серия: География. Геоэкология» и 4 выпуска журнала «География и природные ресурсы». Всего за 2017 год было проанализировано 74 публикации журнала «Вестник Московского университета. Серия 5. География», 84 публикации журнала «Вестник Воронежского государственного университета. Серия: География. Геоэкология» и 88 публикации журнала «География и природные ресурсы». В среднем 


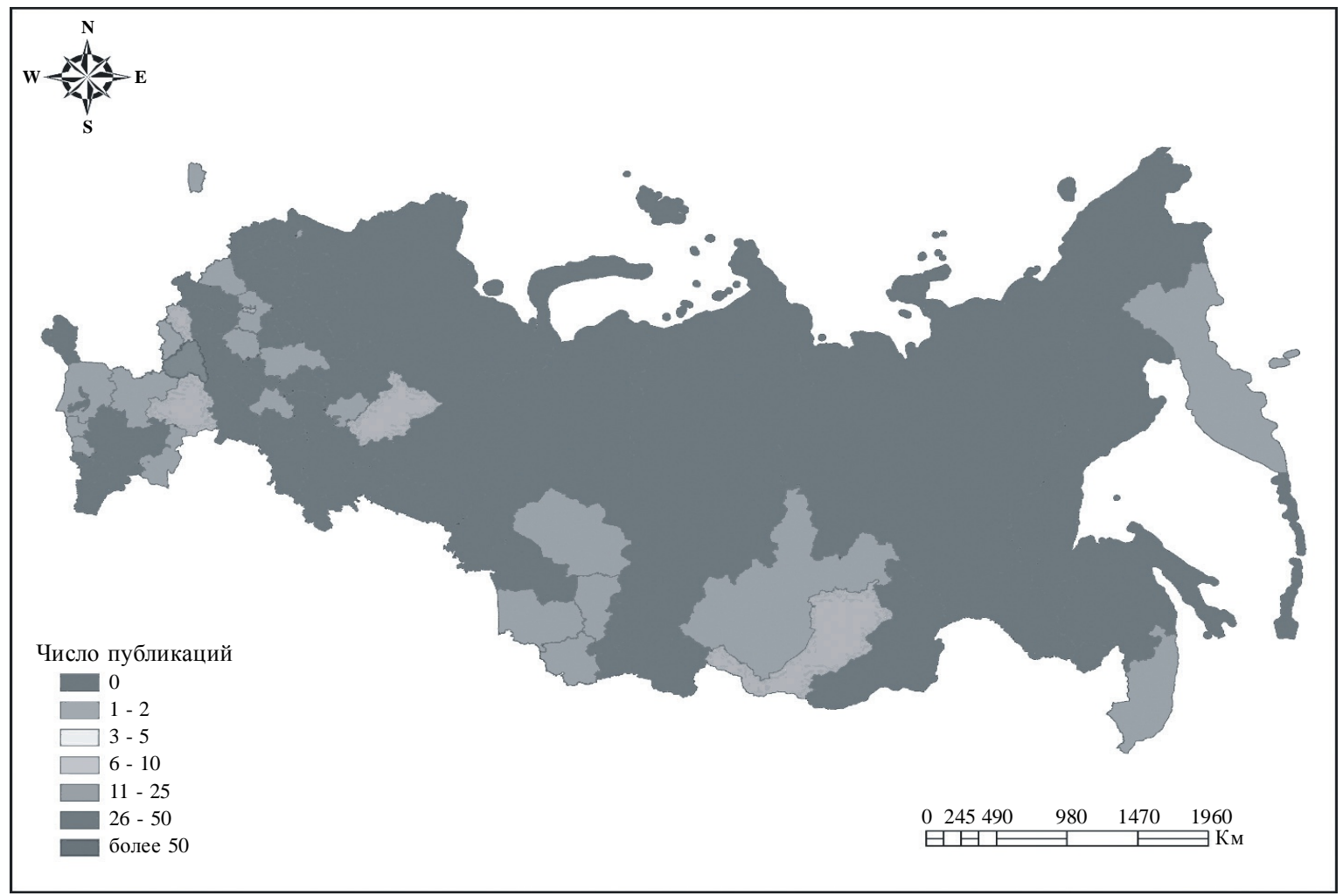

Puc. 2. География публикационной активности журнала «Вестник Воронежского государственного университета. Серия: География. Геоэкология» за 2017 год (построено с использование открытых наборов геоданных - OpenStreetMap)

на один выпуск журнала приходится 12, 21 и 22 публикации соответственно.

При учете того, что рассматриваемые журналы входят в международные базы в каждом из них доминируют российские авторы. Так, в 2017 году в журнале «Вестник Московского университета. Серия 5. География» опубликовали свои работы 192 автора, из которых только 11 представляли зарубежные страны (6\%); в журнале «Вестник Воронежского государственного университета. Серия: География. Геоэкология» опубликовали свои работы 185 авторов, из которых только 15 представляли зарубежные страны $(8 \%)$ и в журнале «География и природные ресурсы» опубликовали свои работы 249 авторов, из которых только 7 представляли зарубежные страны (3\%).

Если говорить о географии зарубежных авторов, то в журнале «Вестник Московского университета. Серия 5. География» доминируют страны дальнего зарубежья (Великобритания, Дания, Финляндия, Швейцария), в журнале «Вестник Воронежского государственного университета. Серия: География. Геоэкология» - страны ближнего зарубежья (Казахстан, Украина, Беларусь, Азербайджан), а в журнале «География и природные ресурсы» как авторы из ближнего (Армения, Беларусь,
Приднестровье), так и дальнего зарубежья (Франция, Вьетнам).

Что касается российских авторов, то они так же представляют не все регионы страны. Большинство авторов тяготеют к организациям, которые располагаются в том же населенном пункте, что и издательство журнала или близлежащим населенным пунктам (за исключением журнала «География и природные ресурсы», хотя здесь нужно сделать оговорку, что журнал входит в группу научных изданий СО РАН, где публикуются большинство авторов, аффилированных с СО РАН).

Так, большинство авторов в журнале «Вестник Московского университета. Серия 5. География» представляют Московский государственный университет имени М.В. Ломоносова, причем практически в каждом номере журнала количество авторов из этого университета больше количества авторов из других университетов (в том числе и зачастую вместе взятых). В журнале «Вестник Воронежского государственного университета. Серия: География. Геоэкология» большинство авторов представляют Воронежский государственный университет, однако доминирование авторов из этого вуза наблюдается только в одном выпуске журнала за 2017 год. В журнале «География и при- 


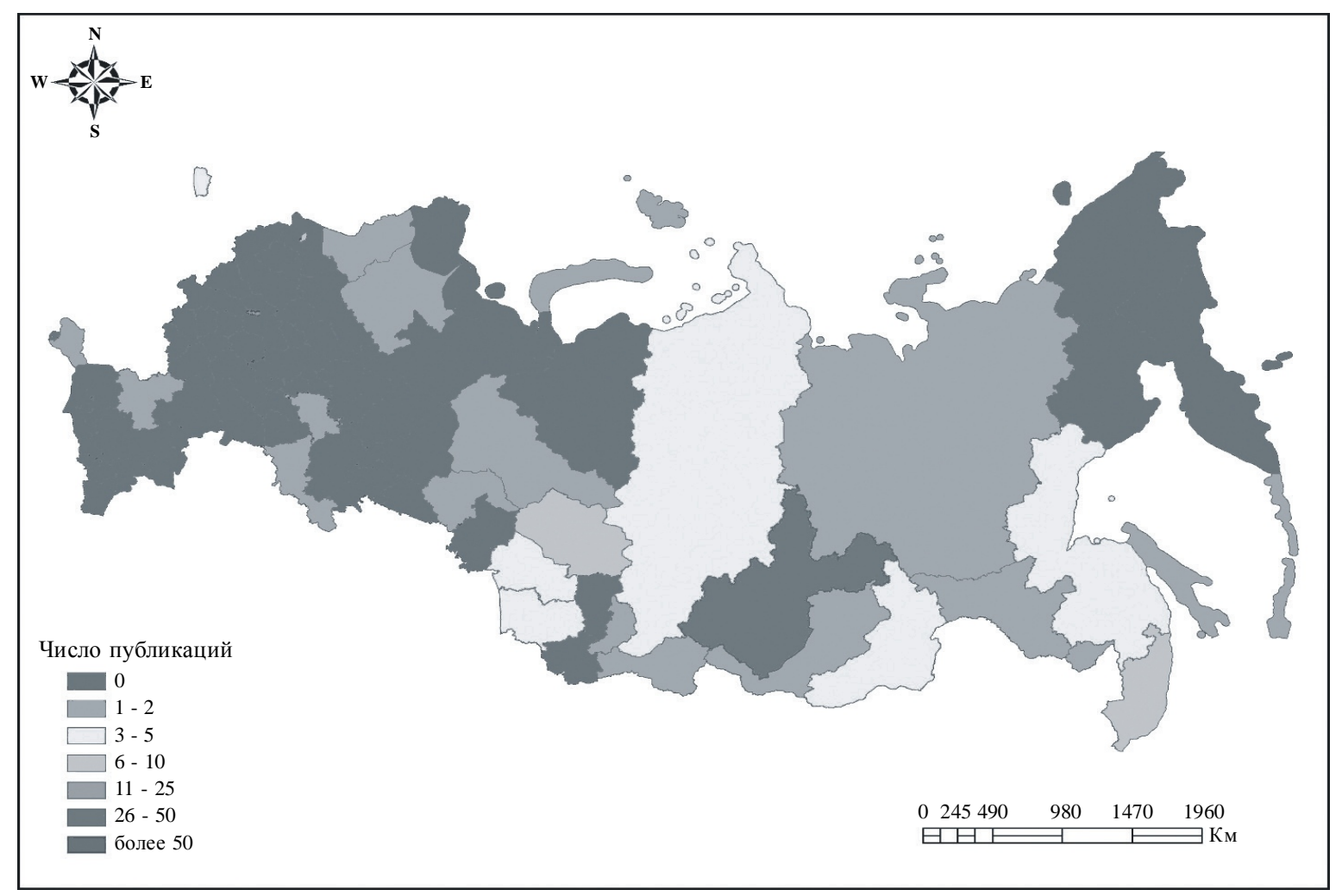

Puc. 3. География публикационной активности журнала «География и природные ресурсы» за 2017 год (построено с использование открытых наборов геоданных - OpenStreetMap)

родные ресурсы» наблюдается большое число авторов из Института географии им. В. Б. Сочавы СО РАН, однако они доминируют только в одном выпуске журнала.

Для анализа публикационной активности по субъектам Российской Федерации были составлены карты, отображающие количество публикаций в рассматриваемых журналах за 2017 год, аффилированых с каждым субъектом (рис. $1,2,3$ ).

Как видно из рисунка 1 география публикационной активности журнала «Вестник Московского университета. Серия 5. География» за 2017 год представлена 19 субъектами Российской Федерации, причем большее количество публикаций приходится на город Москву, которую представляют такие организации как Московский государственный университет имени М. В. Ломоносова, Институт географии РАН, Институт океанологии им. П. П. Ширшова РАН. В целом с городом Москва аффилировано $69 \%$ всех публикаций, вышедших в журнале в 2017 году. Далее с большим отставанием идут Республика Татарстан (3\%), Санкт-Петербург, Томская и Тверская области (по $2 \%$ ).

Как видно из рисунка 2 география публикационной активности журнала «Вестник Воронежского государственного университета. Серия: Гео- графия. Геоэкология» представлена 27 субъектами Российской Федерации, причем большее количество публикаций приходится на Воронежскую область, которую представляют Воронежский государственный университет, Воронежский государственный университет имени Г.Ф. Морозова, Воронежский государственный медицинский университет им. Н.Н. Бурденко, Воронежский государственный педагогический университет. Следует отметить, что география научных организаций, представляющих Воронежскую область, представлена намного шире чем в городе Москва. В целом с Воронежской областью аффилировано $44 \%$ всех публикаций, вышедших в журнале в 2017 году. Далее с большим отставанием идут город Москва, Волгоградская область, Курская область (по 5\%), Пермский край и Республика Бурятия (по $3 \%$ ).

Как видно из рисунка 3 , география публикационной активности журнала «География и природные ресурсы» представлена 26 субъектами Российской Федерации, причем большее количество публикаций приходится на Иркутскую область, которую представляют Институт географии им. В. Б. Сочавы СО РАН, Лимнологический институт СО РАН, Иркутский научный центр СО РАН, Институт систем энергетики им. Л. А. Мелентьева СО 
РАН. Следует отметить, что география научных организаций, представляющих Иркутскую область, намного шире чем в городе Москва, и по количеству примерно соответствует географии Воронежской области. В целом с Иркутской областью аффилировано 30 \% всех публикаций, вышедших в журнале в 2017 году. Далее с небольшим отставанием идут город Москва (10\%), Приморский край $(8 \%)$ и город Санкт-Петербург (6\%).

\section{ВЫВОДЫ}

1. В каждом из рассмотренных журналов наибольшее количество авторов, опубликовавших свои работы приходится из того же субъекта федерации или близлежащих субъектах, в котором так же расположено издательство журнала.

2. Во всех рассмотренных журналах, с учетом того что они входят в международные реферативные базы данных и системы цитирования незначительное число работ от зарубежных авторов.

3. Наиболее обширную географию публикационной активности среди трех рассматриваемых журналов имеют «Вестник Воронежского государственного университета. Серия: География. Геоэкология» и «География и природные ресурсы», а наименьшую - «Вестник Московского университета. Серия 5. География». Так, география публикационной активности журнала «Вестник Московского университета. Серия 5. География» представлена 19 субъектами Российской Федерации (22\% от общего числа субъектов Федерации), журнала «География и природные ресурсы» - 26 субъектами Российской Федерации (31\% от общего числа субъектов Федерации), журнала «Вестник Воронежского государственного университета. Серия: География. Геоэкология» - 27 субъектами Российской Федерации (32\% от общего числа субъектов Федерации).

Финансирование. This work was partially supported by the V.I. Vernadsky Crimean Federal University Development Program for 2015-2024.

\section{СПИСОК ЛИТЕРАТУРЫ}

1. Абрамян А. А. Анализ публикационной активности студентов специальности отраслевой менеджмент по направлению логистика Государственного Университета Управления / А. А. Абрамян // Новая наука : От идеи к результату. - 2016. - № 12-1. - С. 6-10.

2. Абрамян А. А. Анализ публикационной активности студентов специальности отраслевой менеджмент по направлению логистика государственного университета управления / А. А. Абрамян, А. С. Смирнов // Новая наука : Проблемы и перспективы. - 2016. № 121-1. - С. 3-9.
3. Андреева О. Н. Публикационная активность научно-педагогических работников таможенного вуза / О. Н. Андреева // Таможенная политика России на Дальнем Востоке. - 2016. - № 4 (77). - С. 92-101.

4. Алиев Р. Т. Обзор публикационной активности журнала Фронтирных исследований: итоги 2016 года / Р. Т. Алиев // Журнал Фронтирных Исследований. 2016. - № 4. - С. 104-112.

5. Антопольский А. Б. Об исследованиях публикационной активности ученых (на примере членов Российской академии образования) / А. Б. Антопольский, Ю. Е. Поляк // Информационные ресурсы России. 2011. - № 1. - C. 26-30.

6. Воробьев Н. Е. Публикационная активность и оценка качества работы преподавателей высшей школы / Н. Е. Воробьев, Ю. И. Мишенева // Педагогика. 2018. - № 2. - C. 121-125.

7. Гришакина Е. Г. Публикационная активность российских исследователей: университетская наука / Е. Г. Гришакина // Наука. Инновации. Образование. 2016. - № 4 (22). - C. 137-151.

8. Еремченко О. А. Проблема имитации научной публикационной активности в России и рекомендации по ее искоренению / О. А. Еремченко, Ф. А. Кураков // Экономика науки. - 2016. - Т. 2. - № 1. - С. 35-45.

9. Иванов В. В. Государственные инвестиции и публикационная активность вузов: библиометрический анализ / В. В. Иванов, В. А. Маркусова, Л. Э. Миндели // Вестник Российской академии наук. - 2016. - Т. 86. № 7. - С. 611-619.

10. Илиева К. Н. Библиометрический анализ - инструмент измерения публикационной активности ученых и преподавателей / К. Н. Илиева // Современные тенденции развития науки и технологий. -2016 . - № 12 1. - C. 21-27.

11. Логунова О. С. Индексный анализ управления публикационной активностью научно-педагогических работников вуза и его результаты / О. С. Логунова, Д. Я. Арефьева, Е. А. Ильина // Актуальные проблемы современной науки, техники и образования. - 2015. T. 2. - C. 198-204.

12. Логунова О. С. Эффективность управления публикационной активностью профессорско-преподавательского состава института энергетики и автоматизированных систем / О. С. Логунова, Е. А. Ильина // Фундаментальные исследования. - 2016. - № 12-4. C. $748-753$.

13. Марвин С. В. Нормированный показатель публикационной активности, учитывающий количество соавторов научных публикаций / С. В. Марвин // Социология науки и технологий. - 2016. - Т. 7. - № 4. C. 116-133.

14. Михайлов О. В. Опыт определения рейтинга преподавателя с учетом его публикационной активности / О. В. Михайлов // Высшее образование в России. 2016. - № 10. - С. 71-78. 
15. Московкин В. М. Методология оценки региональной публикационной активности и цитируемости на примере университетов Центрального федерального округа Российской Федерации / В. М. Московкин, Я. Лю // Научные ведомости Белгородского государственного университета. Сер. Экономика. Информатика. - 2017. - № 9 (258). - С. 42-52.

16. Преснецова В. Ю. Подсистема получения данных о публикационной активности профессорско-преподавательского состава вуза / В. Ю. Преснецова, Н. А. Загородних, В. М. Пресняков // Научные ведомости Белгородского государственного университета. Сер. Экономика. Информатика. - 2018. - Т. 45. - № 1. С. 159-167.

17. Публикационная активность вузов: эффект проекта «5-100» / О. В. Польдин, Н. Н. Матвеева, И. А. Стерлигов, М. М. Юдкевич // Вопросы образования. -2017. - № 2. - С. 10-35.

18. Сиденко В. П. Оценка публикационной активности журнала «Синергия Наук» / В. П. Сиденко // Синергия Наук. - 2017. - № 8. - С. 440-444.

19. Третьякова О. В. Публикационная активность экономических институтов РАН в свете новых вызовов научной политики / О. В. Третьякова // Экономические и социальные перемены: факты, тенденции, прогноз. 2016. - № 6 (48). - С. 266-287.

20. Хадарцев А. А. Анализ публикационной активности журнала «Вестник новых медицинских технологий (электронный журнал)» / А. А. Хадарцев // Вестник новых медицинских технологий. - 2016. - № 4. - С. 12.

\section{REFERENCES}

1. Abramyan A. A. Analiz publikatsionnoy aktivnosti studentov spetsial'nosti otraslevoy menedzhment po napravleniyu logistika Gosudarstvennogo Universiteta Upravleniya / A. A. Abramyan // Novaya nauka : Ot idei k rezul'tatu. - 2016. - № 12-1. - S. 6-10.

2. Abramyan A. A. Analiz publikatsionnoy aktivnosti studentov spetsial'nosti otraslevoy menedzhment po napravleniyu logistika gosudarstvennogo universiteta upravleniya / A. A. Abramyan, A. S. Smirnov // Novaya nauka : Problemy i perspektivy. - 2016. - № 121-1. - S. 3-9.

3. Andreeva O. N. Publikatsionnaya aktivnost' nauchno-pedagogicheskikh rabotnikov tamozhennogo vuza / O. N. Andreeva // Tamozhennaya politika Rossii na Dal'nem Vostoke. - 2016. - № 4 (77). - S. 92-101.

4. Aliev R. T. Obzor publikatsionnoy aktivnosti zhurnala Frontirnykh issledovaniy: itogi 2016 goda / R. T. Aliev // Zhurnal Frontirnykh Issledovaniy. - 2016. - № 4. S. 104-112.

5. Antopol'skiy A. B. Ob issledovaniyakh publikatsionnoy aktivnosti uchenykh (na primere chlenov Rossiyskoy akademii obrazovaniya) / A. B. Antopol'skiy, Yu. E. Polyak // Informatsionnye resursy Rossii. - 2011. - № 1. - S. 26-30.

6. Vorob'ev N. E. Publikatsionnaya aktivnost' i otsenka kachestva raboty prepodavateley vysshey shkoly /
N. E. Vorob'ev, Yu. I. Misheneva // Pedagogika. - 2018. № 2. - S. 121-125.

7. Grishakina E. G. Publikatsionnaya aktivnost' rossiyskikh issledovateley: universitetskaya nauka / E. G. Grishakina // Nauka. Innovatsii. Obrazovanie. - 2016. - № 4 (22). - S. 137-151.

8. Eremchenko O. A. Problema imitatsii nauchnoy publikatsionnoy aktivnosti v Rossii i rekomendatsii po ee iskoreneniyu / O. A. Eremchenko, F. A. Kurakov // Ekonomika nauki. - 2016. - T. 2. - № 1. - S. 35-45.

9. Ivanov V. V. Gosudarstvennye investitsii i publikatsionnaya aktivnost' vuzov: bibliometricheskiy analiz / V. V. Ivanov, V. A. Markusova, L. E. Mindeli // Vestnik Rossiyskoy akademii nauk. - 2016. - T. 86. - № 7. - S. 611-619.

10. Ilieva K. N. Bibliometricheskiy analiz - instrument izmereniya publikatsionnoy aktivnosti uchenykh i prepodavateley / K. N. Ilieva // Sovremennye tendentsii razvitiya nauki i tekhnologiy. - 2016. - № 12-1. - S. 21-27.

11. Logunova O. S. Indeksnyy analiz upravleniya publikatsionnoy aktivnost'yu nauchno-pedagogicheskikh rabotnikov vuza i ego rezul'taty / O. S. Logunova, D. Ya. Aref'eva, E. A. Il'ina // Aktual'nye problemy sovremennoy nauki, tekhniki i obrazovaniya. - 2015. - T. 2. S. 198-204.

12. Logunova O. S. Effektivnost' upravleniya publikatsionnoy aktivnost'yu professorsko-prepodavatel'skogo sostava instituta energetiki i avtomatizirovannykh sistem / O. S. Logunova, E. A. Il'ina // Fundamental'nye issledovaniya. - 2016. - № 12-4. - S. 748-753.

13. Marvin S. V. Normirovannyy pokazatel' publikatsionnoy aktivnosti, uchityvayushchiy kolichestvo soavtorov nauchnykh publikatsiy / S. V. Marvin // Sotsiologiya nauki i tekhnologiy. - 2016. - T. 7. - № 4. - S. 116-133.

14. Mikhaylov O. V. Opyt opredeleniya reytinga prepodavatelya s uchetom ego publikatsionnoy aktivnosti / O. V. Mikhaylov // Vysshee obrazovanie v Rossii. - 2016. - № 10. - S. 71-78.

15. Moskovkin V. M. Metodologiya otsenki regional'noy publikatsionnoy aktivnosti i tsitiruemosti na primere universitetov Tsentral'nogo federal'nogo okruga Rossiyskoy Federatsii / V. M. Moskovkin, Ya. Lyu // Nauchnye vedomosti Belgorodskogo gosudarstvennogo universiteta. Ser. Ekonomika. Informatika. - 2017. - № 9 (258). - S. 42-52.

16. Presnetsova V. Yu. Podsistema polucheniya dannykh o publikatsionnoy aktivnosti professorsko-prepodavatel'skogo sostava vuza / V. Yu. Presnetsova, N. A. Zagorodnikh, V. M. Presnyakov// Nauchnye vedomosti Belgorodskogo gosudarstvennogo universiteta. Ser. Ekonomika. Informatika. 2018. - T. 45. - № 1. - S. 159-167.

17. Publikatsionnaya aktivnost' vuzov: effekt proekta «5-100» / O. V. Pol'din, N. N. Matveeva, I. A. Sterligov, M. M. Yudkevich // Voprosy obrazovaniya. - 2017. - № 2. - S. 10-35.

18. Sidenko V. P. Otsenka publikatsionnoy aktivnosti zhurnala «Sinergiya Nauk» / V. P. Sidenko // Sinergiya Nauk. - 2017. - № 8. - S. 440-444. 
19. Tret'yakova O. V. Publikatsionnaya aktivnost' ekonomicheskikh institutov RAN v svete novykh vyzovov nauchnoy politiki / O. V. Tret'yakova // Ekonomicheskie i sotsial'nye peremeny: fakty, tendentsii, prognoz. - 2016. № 6 (48). - S. 266-287.

Табунщик Владимир Александрович

старший лаборант кафедры физической географии, океанологии и ландшафтоведения факультета географии, геоэкологии и туризма Таврической академии Крымского федерального университета имени В.И. Вернадского», г. Симферополь, E-mail: tabunshchyk@ya.ru
20. Khadartsev A. A. Analiz publikatsionnoy aktivnosti zhurnala «Vestnik novykh meditsinskikh tekhnologiy (elektronnyy zhurnal)» / A. A. Khadartsev // Vestnik novykh meditsinskikh tekhnologiy. - 2016. - № 4. - S. 12.

Tabunshchik Vladimir Alexandrovich

Senior Laboratory Assistant, Department of Physical Geography, Oceanology and Landscape Science, Faculty of Geography, Geoecology and Tourism, Taurida Academy of the Crimean Federal University named after V.I. Vernadsky, Simferopol, E-mail: tabunshchyk@ya.ru 